\title{
AOR
}

Selected Papers of \#AolR2019:

The $20^{\text {th }}$ Annual Conference of the Association of Internet Researchers Brisbane, Australia / 2-5 October 2019

\section{PANEL: QUEER DE/STABILIZATIONS IN AND OF DIGITAL CULTURAL RESEARCH}

This panel brings together papers that explore digital cultures, platforms, and queer and feminist theoretical and methodological research approaches. The papers in this panel each explore the kinds of approaches suited to researching queer "de/stabilizations" in and of digital culture; that is, to projects of tracing, mapping, and making, queerer worlds via digital cultural research.

"Trustworthy" systems are, in one important sense, systems that are relatively stable, reliable, and that work somewhat predictably. But in algorithmic digital cultures "reliability" and "predictability" are not always characteristics to be trusted: digital media scholars have, for example, examined how algorithmic systems build in, intensify, and thus stabilize a-priori discriminatory practices and cultural associations, power dynamics, and stereotypical representational meanings, thus helping to cement social inequalities via increasingly ubiquitous practices of quantification (O’Neil, 2017; Wachter-Boettcher, 2017). O'Riordan explores this phenomenon in relation to digitally extracted data on "gay" genomics and faces. On a different register, ethnographic research on youth, social media, and gender and sexuality has also evinced the kind of stabilizations of hetero-patriarchal dominant meanings of, for example, digitally shared images of bodies, as Dobson highlights. Important tensions arise in digital cultural research, particularly among scholars concerned with gender and sexuality, around desires to map, trace, and make manifest stable, strong, and more broadly and inclusively "trustworthy" systems, communities, and meanings in digital cultures, and the associated risks of capture and exclusion pertinent to marginalized groups and bodies, as mapped by Race. The papers in this panel explore these tensions, and their implications for digital cultural research.

The panel explores the synergies and tensions between some of the key analytic rubrics we wish to engage when studying digital practices, cultures, and infrastructure. How does queer theory complicate ethnographic and other scholarly approaches to digital practices and identities? What are the overlaps, disconnects, and mutual affordances between actor-network and queer theoretical approaches to queer worldmaking in digital culture, for example, as Race questions? If actor-network theory Suggested Citation (APA): Dobson, A., Race, K., \& O'Riordan, K. (2019, October 2-5). Queer De/Stabilizations Panel. Panel presented at AolR 2019: The $20^{\text {th }}$ Annual Conference of the Association of Internet Researchers. Brisbane, Australia: AolR. Retrieved from http://spir.aoir.org. 
supplies us with a toolbox for tracing the formation of durable, stable, and "trustworthy" worlds and realities, queer theory has always been suspicious of the exclusions and fixations that characterize the worlds, realities, and practices that disciplined subjects are led to trust. Queer theorists once expressed concern about the "fragile and ephemeral" nature of queer culture, the difficulty of "entextualizing it as culture" (Berlant \& Warner, 1998). But in the digital era, it seems, there is no difficulty entextualizing queer and other stigmatized practices, activities, and "criminal intimacies" - these are being converted into digital bits, and extracted, at an unprecedented rate and scale, as O'Riordan's research makes clear. Rather, the difficulty appears to consist now in the material risks such intense processes of entextualization and extraction pose to the lives and standing of those whose practices are criminalized or otherwise sensationalized.

These developments raise several questions of broad significance: Rather than stabilizing those bits of digital culture that are most redolent of queer lives, attachments, and orientations, should destabilization become a critical goal? What sort of orientations or modes of attention to digital infrastructures can we adapt from queer theory, understood as a critical repertoire of destabilizing insights, tactics, methods, and performative activities? Ahmed (2006) has suggested the "queering" of objects is about one's orientation to them so that, for example, a "queer" table is one that is noticed as a table rather than simply used/acted upon. What fades into the background - and what comes curiously into view - when one adopts a queer, perverse, provocative, or playful orientation to digital participation and its material and social infrastructures? Just as importantly, how might the lives of those most vulnerable to digital profiling, surveillance, intimidation, exposure, and abjection be supported in material terms? Is it a matter of building associations, relations, networks, and infrastructures that are somehow more "trustworthy" for marginalized groups and bodies, as actor-network theory might propose? Or does queer survival depend largely on other approaches, such as subverting digital infrastructures, evading its procedures, and scrambling the codes that presently prevail within network societies? Perhaps we need to be attuned to how what seem like stable entities are already being queered constantly. What kinds of interventions, orientations, scholarly approaches, and modes of attention can we devise to query the trustworthiness of digital systems and support those who lives are made most precarious, disgusting, endangered, unbearable, or fragile in digital cultures and networked worlds? The papers in this panel each gesture towards varied possibilities of "queer de/stabilizations" in and of digital cultural research.

\section{References}

Ahmed, S., (2006). Queer Phenomenology. USA: Duke University Press

Berlant, L. \& Warner, M. (1998). Sex in public. Critical Inquiry 24 (2), 547-566.

O'Neil, C. (2016). Weapons of math destruction: how big data increases inequality and threatens democracy. New York: Crown.

Wachter-Boettcher, S. (2017). Technically Wrong: Sexist Apps, Biased Algorithms, and Other Threats of Toxic Tech. New York: W. W. Norton \& Company. 


\title{
RE/ORIENTATIONS TOWARDS YOUTH (OVER)SHARING, (NON)AGENCY, AND SOCIAL MEDIA: QUEER APPROACHES AND DE/STABILISATIONS OF GENDER AND SEXUALITY IN YOUTH DIGITAL CULTURES?
}

\author{
Dr Amy Dobson, Curtin University
}

This paper draws on data from two research projects exploring youth sexting practices and social understandings of gender roles around social media use in youth cultures in Australia in order to explore broader methodological questions about the kind of approaches and analysis that might help to better trace, understand, and contribute to "queer de/stabilisations" of gender and sexuality in youth social media cultures in future research. The first project involved focus groups with students in years 10-12 at two high schools; the second, interviews with parents and teachers about their perceptions of gender roles and pedagogies as regards youth digital cultures.

Participation in social media has become near imperative for many young people. Yet discourses about social media participation are still largely framed as being about the individual choices and responsibilities of users, especially young people; that is, about human agency. For marginalized youth in particular, connection via social media is often framed in terms of promises of empowerment and self-expression, if not social capital and direct mobility (Dobson, Carah, \& Robards, 2018), in line with the promises of "interactive" and "participatory" culture more broadly (Banet-Weiser, 2012; O'Riordan, 2017). In late modern societies characterised by the prevalence of therapeutic discourses for understanding the self and subjectivity, an ability to narrate and to "show/display" the self "transparently" and "authentically" is seen as key to personal happiness (Illouz, 2007), personal empowerment, and trustworthiness, particularly for young women (Harris, 2004). Such psychological and therapeutic discourses for understanding the self and internality dovetail with and are intensified and commodified via the kind of mass self-communication (Castells, 2007) social media facilitates and mandates. I highlight, firstly, the need to understand social media participation and selfrepresentation beyond simplistic notions of human agency and choice in this context, and to conceptualize media practices of sharing, oversharing, as well as limited selfdisclosure and non-participation, as structured by existing social axes of inequality, as evidenced in existing literature on how sexuality and gender mediate young people's use of social media (Pascoe, 2011; Duguay, 2014; Rubin \& McClelland, 2015; Albury \& Byron, 2014; Ringrose, 2013; Dobson, 2015; Kanai, 2018). To take marginalization more fully into account in the current era of widespread and oft-required social media participation is to think beyond digital divides of access and literacy to how social axes of inequality and intersecting embodied identities structure "emotional intelligence and habitus" (Illouz, 2007), and thus the very capacity for a kind of "transparent" self- and/or bodily revelation, as well as reflexive choices about the safety and risks involved in such.

Feminist psycho-social and new-materialist approaches to youth social media use are particularly helpful in complicating notions of youth participation beyond the conscious, the individual, and the human (Ringrose, 2013; Warfield, 2017). But where algorithmic 
media platforms are the communicative infrastructure, there is a need to better account for the agentic capacities of digital infrastructure itself (Carah and Angus, 2018).

Bringing psycho-social and new materialist feminist approaches more directly into conversation with the kind of approaches suggested in actor-network theory towards mapping the stabilizations of communicative and algorithmic digital infrastructure and the networks of human and non-human actancts involved in such processes could be helpful in this regard. Race's (2019) propositions about the possibilities of a "queered actor network theory" for better mapping the interplay of bodies and non-human infrastructure, or what O'Riordan (2017) terms "biodigital life", in unpredictable and possibly serendipitous digital encounters is particularly relevant here. A queered actornetwork theory might be particularly useful for tracing the human expressions as well as non-human algorithmic infrastructures that constitute youth acts of digital "attention seeking" (a phrase used frequently in the data by both young people and adults to describe digital sharing practices deemed "excessive"); for understanding assemblages of attention and attention seeking that are constituted by shifting networks of human expressions, digital inscriptions of attention, devices, and platform algorithms designed to register and channel human attention and affect.

I offer some consideration the kind of questions and analytical reading of, sometimes quite explicitly sexualized, everyday youth social media participation that might be ethically mandated in this context. I suggest that in such socially striated and digitally collapsed contexts, a kind of "reparative reading" of youth social media practices (following Wiegman, 2014, on Sedgwick), especially acts and practices of "seeking attention", is politically important; so too, an ethics of "queer comradery and generosity" (Warner cited in Albury, 2017). The kind of approach to data analysis and future research I want to suggest is one concerned, firstly, with asking where and how both the less-than-conscious and the non-human actants might "show up", or make appearances, in data on youth social media practices, with discussion of some examples from our data. Secondly, it is concerned with asking where moments or possibilities of "queer de/stabilizations", "re-oreintations", and other modes of attention arise, following Race (2019) - around images of bodies, discourses about them and about gender roles, as well as discussions of digital objects themselves, like phones or laptops. Again here, some illustrative examples are discussed.

\section{References}

Albury, K. (2017). Just because it's public doesn't mean it's any of your business: Adults' and children's sexual rights in digitally mediated spaces. New Media \& Society, 19(5), 713-725.

Albury, K., \& Byron, P. (2014) Queering sexting and sexualisation. Media International Australia, 153(November): 138-147.

Banet-Weiser, S. (2012). AuthenticTM: The politics of ambivalence in a brand culture. New York: NYU press.

Berlant, L., 2008. The female complaint. Duke University Press. 
Carah, N., \& Angus, D. (2018). Algorithmic brand culture: participatory labour, machine learning and branding on social media. Media, Culture \& Society, 40(2), 178-194. doi: $10.1177 / 0163443718754648$

Castells, M. (2007). Communications, Power and Counter-power in the Network Society. International Journal of Communications. 1, 238-366.

http://ijoc.org/index.php/ijoc/article/view/46

Dobson, A. S. (2015). Postfeminist Digital Cultures: Femininity, Social Media, and SelfRepresentation. New York: Palgrave Macmillan.

Dobson, A. S., Robards, B. \& Carah, N. (eds.) (2018) Digital Intimate Publics and Social Media. New York: Palgrave.

Duguay, S. (2014). "He has a way gayer Facebook than I do": Investigating sexual identity disclosure and context collapse on a social networking site. New Media \& Society, 18(6), 891-907.

Illouz, E. (2007). Cold Intimacies: The Making of Emotional Capitalism. Oxford: Polity.

Kanai, A (2019) Gender and Relatability in Digital Culture: Managing affect, intimacy and value. Basingstoke: Palgrave Macmillan.

O'Riordan, K. (2017). Unreal Objects: Digital Materialities, Technoscientific Projects and Political Realities. UK: Pluto Press.

Pasco, C.J. (2011). Resource and risk: Youth sexuality and new media use." Sexuality Research and Social Policy 8(5), 5-17.

Race. K. (forthcoming). What possibilities would a queer actor-network theory generate? In The Routledge Companion to Actor Network Theory, edited by Anders Blok, Ignacio Farias and Celia Roberts.

Ringrose, J. 2013. Postfeminist Education? Girls and the Sexual Politics of Schooling. New York: Routledge.

Ringrose, J., Harvey, L., Gill, R., \& Livingstone, S. (2013). Teen girls, sexual double standards and 'sexting': Gendered value in digital image exchange. Feminist Theory, 14(3), 305-323.

Rubin, J. D., \& McClelland, S. I. (2015). 'Even though it's a small checkbox, it's a big deal': stresses and strains of managing sexual identity(s) on Facebook. Culture, Health \& Sexuality, 17(4), 512-526.

Warfield, K. (2017). "I Set the Camera on theHandle of My Dresser": Re-Matter-lalizing Social Media Visual Methods through a Case Study of Selfies. Media and Communication 5 (4), 65-74. 
Wiegman, R. (2014). The times we're in: Queer feminist criticism and the reparative 'turn'. Feminist Theory 15(1), 4-25.

\title{
QUEER ACTOR-NETWORK THEORY: CAN WE TRUST SEX TO DESTABILIZE THINGS?
}

\author{
Professor Kane Race, University of Sydney
}

'Trust in the system' might be said to depend on having stable and predictable arrangements in place that give people the capacity to do what they normally want or need to do. The concept of infrastructures, including the increasing array of infrastructures that involve or depend upon digital practices, has recently gained traction in queer studies that draws on actor-network theory (ANT) and 'combines material and symbolic domains, eschews technological determinism, and recognizes both systematicity and failure' (Wilson 2016, p. 249). This paper grapples with tensions and critical synergies between systematicity and failure, exploring the connections, friction, and divergences between these two branches of contemporary social and cultural theory that have become particularly prominent within studies of digital culture and networked societies: ANT and queer theory.The ethnographic approach to the making of science, technology, facts, and realities that is a hallmark of ANT produces different emphases and critical stances than those typically found in queer theory. ANT proceeds by attending to the material associations and practical relations that transform contingent relations into durable, concrete realities. It is distinguished by the precision with which it attends to sociomaterial arrangements Foucault once termed dispositifs to give them consequential form, exploring their provisional nature, contingencies, particularities and multiplicities.

Queer theory has a keener sense of the ways in which established institutions, norms, conventions, and narratives damage the material prospects, social standing, and overall lives of those subject to regimes of gender and sexuality (among other disciplinary categories). It takes as given, however, the overarching power of the ideological, normative, disciplinary, discursive and/or psychic structures that produce certain lives as abject, vulnerable, and suspect within prevailing social worlds on this basis. Indeed, queer theory's favoured strategies of dismantling, countering, subverting, exposing or otherwise disrupting hegemonic norms have led leading critics within its own ranks to question the field on the 'overdetermined relationalities' of the normative, disciplinary structures it takes as objects of critical attention (Wiegman \& Wilson 2015, p. 10). They cite Berlant and Warner's canonical essay 'Sex in Public' to suggest queer theory sets up an oppositional dynamic that neglects the complex relationalities and 'diverse consociating nature of normativity' and explore the possibility of queer theory without normativity. In fact 'Sex in Public' is quite clear that heteronormativity does not refer to 'anything like a simple monoculture' and 'never has more than a provisional unity' (Berlant \& Warner, 1998, p. 552). But what is also glossed over by its critics is the seemingly flip attention to material objects and practices ('paying taxes, being disgusted, philandering, bequeathing, celebrating a holiday, investing for the future, teaching, disposing of a corpse, carrying wallet photos, buying economy size, being 
nepotistic, running for president, divorcing, or owning anything "His" and "Hers"). These activities are framed as material practices that 'though not explicitly sexual, are implicated in the hierarchies of property and propriety' dubbed heteronormativity, and their elaboration marked as 'a project for further study' (p. 555).

Queer attention to material practices is echoed in recent work by Sara Ahmed that conceives heterosexual privilege and racial capitalism as elaborate support systems that create a 'buffer zone' (2014): 'When a whole world is organised to promote your survival, from health to education, from the walls designed to keep your residence safe, from the paths that ease your travel, you do not have become so inventive to survive' (2014). Queer theory's concern with the arrangement and experience of sexual, gendered, racialized bodies has given it a sensitivity to certain non-human actants, the material significance of which ANT has helped many fields bring more sharply into view. Brian Larkin defines infrastructures as 'objects that create the grounds on which other objects operate' before making the suggestive claim that 'their peculiar ontology lies in the fact that they are things and also the relation between things' (2013, p. 329). ANT's insistence on the contingency of relations among human and non-human actants might help break the stranglehold of totalization sometimes said to characterize queer theorists' take on heteronormativity.

Worlds capable of sustaining queer lives are commonly considered to be composed of cultures, communities, arrangements and/or publics that queer theorists characterise as 'fragile and ephemeral' (Berlant \& Warner 1998, p. 561). Arguably ANT could be adapted to remedy such fragility by providing insights into how stronger worlds or realities are built and sustained. But this paper takes a different approach and proposes that ANT could benefit just as significantly from a better appreciation of the critical necessity and/or disruptive effects of worlds 'assembled out of the experience of being shattered,' as Ahmed puts it (2014). Queer digital networks involve something more or other than assembling a more stable and durable world for certain minoritized subjects, in other words. They make connections where 'unexpected things can happen' and by promoting acknowledgement of the fears and pleasures entailed in exposure to alterity, rather than eschewing such contradictions. This may involve disassembling or interfering with certain established protocols, arrangements, functions and designs: those techniques devised to keep people (and the nonhumans they are connected to) 'in line'.

Deleuze and Guattari make a distinction between different kinds of assemblages that may help specify what is distinctive about queer ANT. Specifically, they distinguish between molar (or arborescent) assemblages which they conceive as organised, hierarchized, consolidated, unified, binarized and divisible (i.e. more or less stable institutions) - and rhizomatic (or molecular) assemblages which are by contrast unpredictable, unsystematic, flexible, flighty, horizontal, non-binary and indivisible without changing their nature (i.e. ephemeral). Where molar assemblages stratify, territorialize, hierarchize, binarize and subjectify, molecular assemblages involve processes of de-stratification, de-territorialization, de-subjectification, molecularization and scrambling. Further, these rhizomatic structures are characterised by unpredictable 'lines of flight' that can be generative or perilous depending on what they connect up with in the course of such trajectories (Deleuze \& Guattari, 1987). Given the radical, 
anti-establishment commitments of Deleuze and Guattari's politics, readers tend to invest rhizomatic and molecular processes with greater critical value, though on closer inspection all assemblages have stratifying and de-stratifying tendencies. I would contend at any rate that ANT has largely focused on the emergence of molar assemblages: the construction and elaboration of actor-networks that become stable enough to produce durable technologies, effective mediations and scientific 'facts' - or else fail to do so, with this failure emerging as a missed opportunity or instructive example of how things go wrong.

Queer theory has a more conflictual and contradictory set of critical investments. Its hankering for sociomaterial arrangements that better support queer lives is complicated by its sensitivity to the fact that any process of stratification or stabilization (any molar assemblage) runs the risk of producing its own misfits and shutting them out - i.e. other queers whose needs and lives are not serviced by what is set up. Queer theory's critical relation to institutions and established structures that embattle queer forms of life means that it is just as interested in disassembling the social (as it is currently constituted) as reassembling it or tracing the associations that make, reproduce and sustain it. Disruption, deviation, destabilization and failure tend to be invested with some political value in this literature, rather than being framed as problems or missed opportunities as we see in ANT. The paper concludes by suggesting recent framings of sex as play (Paasonen 2018; Race 2018). Sexual play might be regarded as particularly prolific scenes of associative activities, not only because of their promiscuous and labile nature and the sheer multiplicity of the associations they can generate, but also their capacity to disorganize and reconfigure attachments, identities, relations and ontologies.

\section{References}

Ahmed, S., (2006). Queer Phenomenology. Duke University Press.

Ahmed, S., (2014). Selfcare as Warfare."

https://feministkilljoys.com/2014/08/25/selfcare-as-warfare/

Berlant, L. and Warner, M., (1998). Sex in public. Critical inquiry, 24(2), pp.547-566.

Deleuze, G. and Guattari, F., (1987). A Thousand Plateaus. Minneapolis: University of Minnesota Press.

Larkin, B., (2013). The politics and poetics of infrastructure. Annual review of anthropology, 42, p.327-343.

Latour, B. (2005). Reassembling the Social. London: Oxford UP

Paasonen, S., (2018). Many Splendored Things: Thinking sex and play. London: Goldmsiths.

Race, K., (2017). The gay science: Intimate experiments with the problem of HIV. Routledge. 
Wiegman, R. and Wilson, E.A., (2015). Introduction: Antinormativity's queer conventions. differences, 26(1), p.1-25.

Wilson, A., (2016). The infrastructure of intimacy. Signs 41(2), p.247-280.

\section{SEXUALITY AND THE (DE)STABILIZING CAPACITY OF ALGORITHMS}

\section{Professor Kate O'Riordan, University of Sussex}

This paper examines the stabilization and destabilization of constructions of sexuality through algorithmic forms. It examines the construction of sexuality as identity through consumer genomics on the one hand and facial recognition on the other. The focus is on two recent controversies, emerging from co-located research communities in Silicon Valley. Image recognition algorithms and genome sequences are produced in these sites and the ensuing circulation and consumption of these constitute new sites of address (Warner, 2005; Butler, 2009). These can be opened up to look at meaningmaking practices across these forms and to examine the ways in which they are generative of identities in an economy of extraction (Cooper, 2011; Jarrett, 2015).

Recently, consumer genomics company 23andMe turned their attention explicitly to sexuality research (together with UK Biobank and the Broad Institute). At the same time Stanford based researchers Michael Kosinki and Yilun Wang (2017) announced the findings of sexuality research based on the capacity of the same extractive digital infrastructure. The two sites deployed very different methods, ethics, results and projections, and this paper considers how they both construct the public good in different ways. This turn to sexuality research in both the name of genomics and health research on the one hand, and in the context of marketing surveillance technologies on the other, demonstrates some constitutive contradictions in the (de)stabilization of sexuality itself.

The 23andMe project constructed knowledge about LGBT populations as a good, and shifted from this to a discourse about inclusion in the work place as good science. Discrimination was cast as undermining the public good because of excluding great minds from the scientific endeavor. At the same time this evoked the implicit risk of excluding what they referred to as 'nonheterosexual' behavior from the genome itself. In October of last year results from the 23andMe research were announced in terms which were careful to avoid and contest the language of the gay gene which dominated genetic sexuality research in the 1990s. Andrea Gann from The Broad Institute was very careful to stress that this work has no predictive power. This contrasts very strongly and deliberately with another piece of sexuality research announced the previous year.

The Kosinski and Wang (2017) research has become referred to in some places as the Gay Face research and the amount of attention it garnered, as well as co-location, made it important that the 23andMe researcher was able to distance itself from this. Kosinski and Wang and the researchers scraped dating sites for profile pictures of men seeking sex with men, and then cleaned the data by selecting for white, human, and clearly either male or female head shots. It constructed the public good as knowledge 
about the power of technology. The researcher made the case that the research was important, firstly because it provided evidence of the power of face recognition technologies and algorithms, and secondly because gay populations should be warned that they can be identified and discriminated against by hostile surveillance systems.

These two examples speak to questions about extraction, digital infrastructure, stabilizations, and public good in particular ways. Extraction then can be thought of as a mode of interactivity, central to life as mediation (Kember and Zylinksa, 2012). These forms of address construct public good in terms of decontexualized knowledge on the one hand, and responsibly contextualized knowledge on the other. The forms of extraction matter and so does the question of what moves, and what is displaced and replaced. Identities are reconfigured here and stabilized in particular ways. Profile photos and forms of self-representation are taken to create knowledge about how people look. Forms of identity and identification are taken to construct identity categories, and readers of these texts and audiences of their address take these up in contested, furious, and affirmative ways. On the one hand this is the displacement of identity by phrenology, which extracts via representation and replaces with identity categories. On the other hand, by taking DNA and attributing it to behaviors this takes from identities and replaces with potentially open and new categories of person. For example, the somewhat empty category of the non-heterosexual, which is likely to be re-read as gay in any case, or the more specific identity of the good researcher. This case as a whole extracts multiple elements via social media materials, plus DNA (via saliva), and moves them into informational forms. Those forms are data points, which can be measured as units and put together with results to constitute algorithms and say things about people through an address.

Identifying sexuality through sexual behavior points to anxieties about reproduction, which biodigital technologies promise to reconfigure so absolutely that the links between sexual acts and human reproduction might be severed. On the other hand, they promise future attachments to social orders regulated through the identification of sexual behaviors. The identification of sexual acts as traits read through both genotype and phenotype come together in these projects: the genomic research tries to deconstruct its own research question and stabilize the category of nonheterosexual, whilst the image recognition algorithm recasts gay and straight as meaningful. Both offer forms of address that are momentarily stabilized through engaging publics, whether compliant or resistant. Luciana Parisi (2004) indicated that the biodigital was a new kind of layer or substrate in the world created from a kind of tipping point of bio-digital integration. However, we might more productively think about it as an already existing infrastructure that corporealizes information and makes materials informatic whilst temporarily stabilizing informed material movements. It is those temporary (de)stabilizations and intensifications, particularly around the question of who we think we are, and how we are captured or moved on, that makes a difference to both the present and the future of (algorithmic) identity.

\section{References}

Butler, J. (2009). Giving an Account of Oneself. Fordham University Press Cooper, M (2011) Life as Surplus: Biotechnology and Capitalism in the Neoliberal Era. University of Washington Press. 
Jarrett, K. (2015). Feminism, Labour and Digital Media: The Digital Housewife. Routledge.

Kember, S. and Zylinksa, J. (2012). Life After New Media: Mediation as a Vital Process. MIT Press.

Kosinski, M. and Wang, Y. (2018). Deep Neural Networks Are More Accurate Than Humans at Detecting Sexual Orientation From Facial Images. Journal of Personality and Social Psychology. February, 114(2): 246-257

Parisi, L. (2004). Abstract Sex, Philosophy, Biotechnology and the Mutations of Desire. Continuum.

Warner, M. (2005). Publics and Counter publics. Zone Books. 